\title{
A STUDY OF HIGH SENSITIVITY C-REACTIVE PROTEIN (hS-CRP) LEVELS IN CEREBROVASCULAR ACCIDENT (STROKE)
}

\author{
Peddi Bhaskar'1, Bikshapathi Rao ${ }^{2}$, Rajender ${ }^{3}$
}

${ }^{1}$ Associate Professor, Department of Medicine, KMC/MGM Hospital, Warangal Dist., Telangana State. ${ }^{2}$ Associate Professor, Department of Medicine, KMC/MGM Hospital, Warangal Dist., Telangana State. ${ }^{3}$ Postgraduate, Department of Medicine, KMC/MGM Hospital, Warangal Dist., Telangana State.

\section{ABSTRACT}

World Health Organization (WHO) defined stroke as "rapidly developing clinical signs of focal or global disturbance of cerebral function, lasting more than 24 hours or leading to death with no apparent cause other than vascular origin."

\section{OBJECTIVES}

The purpose of this study was to determine the frequency of raised hs-CRP levels in patients with first-ever acute ischaemic and haemorrhagic stroke. To evaluate the ability of hs-CRP levels as a biomarker to differentiate between haemorrhagic and ischaemic stroke. To evaluate whether hs-CRP levels in stroke correlate with other risk factors.

\section{BACKGROUND AND OBJECTIVE}

Cerebrovascular accident, which has considerable mortality and morbidity deserves attention towards its prevention. The first line of defence in stroke prevention are detecting and adequately treating manageable risk factors.

\section{METHODS}

This is a cross-sectional study; 100 consecutive acute stroke patients who presented within 12 hrs. to the MGM Hospital Warangal, Telangana, are considered in this study.

\section{RESULTS}

There were 71 ischaemic stroke patients and 29 haemorrhagic stroke patients in whom all ischaemic stroke patients $71(100 \%)$ and 29 (32\%) haemorrhagic stroke patients has high hs-CRP (3 mg/L).

\section{CONCLUSION}

HS-CRP appears to be an important risk factor for both acute ischaemic stroke and haemorrhagic stroke. HS-CRP levels are considerably higher in ischaemic stroke patients compared with haemorrhagic stroke patients, which can be a useful marker to differentiate ischaemic and haemorrhagic stroke.

\section{KEYWORDS}

High sensitive C-Reactive Protein.

HOW TO CITE THIS ARTICLE: Bhaskar P, Rao B, Rajender. A study of high sensitivity C-reactive protein (hs-CRP) levels in cerebrovascular accident (stroke). J. Evolution Med. Dent. Sci. 2016;5(65):4655-4660, DOI: 10.14260/jemds/2016/1061

\section{INTRODUCTION}

World Health Organization (WHO) defined stroke as "rapidly developing clinical signs of focal or global disturbance of cerebral function, lasting more than 24 hours or leading to death with no apparent cause other than vascular origin. ${ }^{1,2}$

Cerebrovascular diseases include some of the most common and devastating disorders: ischaemic stroke and haemorrhagic stroke. ${ }^{3}$ Stroke manifests by various neurological signs and symptoms depending on extent, area of involvement and the underlying cause. These include coma, hemiplegia, paraplegia, monoplegia, cranial nerve palsy, speech disturbance, sensory impairment, etc. Of these, hemiplegia is the most common presentation seen in about $90 \%$ of patients. ${ }^{1}$

Financial or Other, Competing Interest: None.

Submission 13-07-2016, Peer Review 30-07-2016,

Acceptance 02-08-2016, Published 13-08-2016.

Corresponding Author:

Peddi Bhaskar,

Flat No.: 303, Door No.: 13-1-133,

Sai Towers, Matwada,

Warangal- Dist., Telangana State.

E-mail: bhaskar_peddi2003@yahoo.co.in

DOI: $10.14260 /$ jemds/2016/1061

\section{MORBIDITY AND MORTALITY}

Stroke is the second leading cause of death worldwide causing 6.2 million deaths in 2011 and is double the rate of heart disease in China. Strokes cause $\sim 200,000$ deaths each year in the United States and are a major cause of disability. ${ }^{3}$ Among adults of age group 35 to 44 , the incidence of stroke is 30 to 120 of 100,000 per year and for those aged 65 to 74 the incidence is 670 to 970 of 100,000 per year. 4

Stroke is becoming an important cause of premature death and disability in low-income and middle-income countries like India, largely driven by demographic changes and enhanced by the increasing prevalence of the key modifiable risk factors. ${ }^{5}$ Thus stroke, which is associated with considerable morbidity and mortality, deserves attention towards its prevention. The first lines of defence in stroke prevention are detecting and adequately treating manageable risk factors. An increasing body of evidence has linked inflammation with the pathogenesis of atherothrombotic stroke. Infection and inflammation may promote atherosclerosis and thrombosis by elevating serum levels of CRP, fibrinogen, leukocytes, clotting factors and cytokines and by altering the metabolism and functions of endothelial cells, monocytes and macrophages. Low grade infections reflected in elevated levels of various 
acute-phase proteins might be partly responsible for the inflammatory processes observed in atherosclerotic lesions, 6,7 which in turn may relate to the occurrence of ischaemic symptoms. Hypertension and atherosclerosis interact in a variety of ways and causes haemorrhagic stroke.

Atherosclerosis and hyperglycaemia by reducing the resilience of large vessels induces hypertension and hypertension worsens atherosclerosis. ${ }^{8}$

Several clinical trials have showed an association between high concentration of serum C-reactive protein and ischaemic strokes. ${ }^{9,10}$ In this regard, we found very few studies in haemorrhagic stroke. ${ }^{11,12} \mathrm{C}$-Reactive Protein, an acute-phase reactant, is an indicator of underlying systemic inflammation and a novel marker for atherothrombotic disease. ${ }^{13}$ Ridker et $\mathrm{al}^{14}$ first reported that C-Reactive Protein level predicts future myocardial infarction and stroke. Ridker et al concluded from a prospective study of 27,939 apparently healthy women, comparing serum levels of C-reactive protein and LDLcholesterol that the C-reactive protein level is a stronger predictor of cardiovascular events than the LDL cholesterol level and that C-reactive protein and LDL-cholesterol were minimally correlated. ${ }^{15}$ Finally, the research findings linking Creactive protein to atherosclerotic cardiovascular disease (Comparing C-reactive protein with lipids) have mostly focused on coronary heart disease or have used cardiovascular events (Encompassing total coronary heart disease, non-fatal myocardial infarction or stroke and coronary revascularization procedures) instead of stroke as the specific outcome of interest and there have been only a few large-scale prospective epidemiological studies of stroke. In the present study, an attempt is made to study the levels of hs-CRP levels in acute stroke, and an attempt has been made to correlate serum hs-CRP levels and risk factors in stroke.

\section{OBJECTIVES}

1. The purpose of this study was to determine the frequency of raised hs-CRP levels in patients with first-ever acute ischaemic and haemorrhagic stroke.

2. To evaluate the ability of hs-CRP levels as a biomarker to differentiate between haemorrhagic and ischaemic stroke.

3. To evaluate whether hs-CRP levels in stroke correlate with other risk factors.

\section{METHOD OF COLLECTION OF DATA}

The study is a Cross-Sectional Study in which cases are selected taking into consideration inclusion and exclusion criteria. Detailed history was taken, Clinical examination was done as per proforma and investigations were done.

After obtaining an informed consent, a total of 100 patients with first-ever acute ischaemic stroke, aged 28 years and above and of either gender were included by consecutive sampling technique. Patients presenting with recurrent stroke and those who were admitted more than 12 hours after the onset of symptoms were excluded from the study. Acute stroke was diagnosed clinically and radiologically as follows: A focal neurological deficit (Hemiparesis, dysphasia, cranial nerve palsies or hemianopia) of sudden onset that persists beyond 24 hours and documented by a brain CT scan or MRI indicating the presence of infarction or haemorrhage. Patients were assessed through a detailed history (From the patient or from relatives) including personal particulars, presenting complaints, past history of stroke, smoking, alcohol consumption, hypertension, statin use and diabetes mellitus.
Blood sample was taken for hs-CRP at the time of admission and measured using nephelometry after radiological confirmation of stroke.

Hypertension was defined as history of HTN or current antihypertensive therapy.

Diabetes was defined as history of DM or current antidiabetic therapy.

Dyslipidaemia was defined as a total cholesterol level $\geq 200$ $\mathrm{mg} / \mathrm{dL}$ or current cholesterol-lowering therapy.

Smokers is defined as current or previous history of smoking.

Alcoholism is defined as a current or previous history of alcoholism.

Outcome is recorded after 3 weeks as survival and nonsurvival.

\section{Inclusion Criteria}

All patients of first ever CT proven stroke, who were admitted within 12 hours of symptom onset.

\section{Exclusion Criteria}

Patients with following conditions (Identified by history, clinical examination and investigations) are excluded from the study.

- Patients who presented after 12 hours of symptom onset.

- Patient with previous CVA and MI.

- Acute infectious disease.

- Osteoarthritis, costochondritis, rheumatoid arthritis, ankylosing spondylitis and other disorders.

- Known or suspected neoplastic disorders.

- Recent (Less than 3 months) major trauma, burns, surgery.

- Patients taking and steroids and OCPs.

- Patients with hepatic and renal failure.

\section{RESULTS}

There were 71 ischaemic stroke patients and 29 haemorrhagic stroke patients in whom all ischaemic stroke patients 71 (100\%) and 29 (32\%) haemorrhagic stroke patients has high hs-CRP ( $3 \mathrm{mg} / \mathrm{L})$. Mean hs-CRP levels in ischaemic stroke was $7.32 \pm 2.92 \mathrm{mg} / \mathrm{L}$ and haemorrhagic stroke was $2.65 \pm 0.77$ $\mathrm{mg} / \mathrm{L}$ which was statistically significant $(\mathrm{p}<0.001)$. In this study hypertension - 46 is the leading risk factor followed by diabetes - 38, dyslipidaemia - 36, alcoholism - 35 and smoking $-32 ; 93 \%$ of hypertensives, $86.8 \%$ diabetics, $94 \%$ dyslipidaemic patients, $82 \%$ alcoholics and $83 \%$ smokers have more than $3 \mathrm{mg} / \mathrm{L} \mathrm{hs-CRP.} \mathrm{Difference} \mathrm{mean} \mathrm{hs-CRP} \mathrm{in} \mathrm{all}$ stroke patients with above risk factors is statistically significant. The difference is statistically significant in ischaemic stroke also, but in haemorrhagic stroke patients only hypertensive patients have significant high levels of hsCRP. The difference in mean hs-CRP levels is considerably higher in non-survivor than survivor.

\section{METHODOLOGY}

\section{Source of Data}

Hundred consecutive patients who presented with diagnosis of first ever stroke within 12 hrs. to MGM Hospital, Warangal, Telangana.

\section{Period of Study}

Jan 2014 to July 2015.

Study Design: Cross-Sectional Study. 


\section{Protocol of the Study}

For every case of clinical data, appropriate radiological investigations and results of routine investigations were prospectively recorded. Blood sample was taken for C-reactive protein by performing venepuncture and estimation was done. Specimens were collected in siliconised vacuum glass tubes. Tubes were centrifuged at 3,000 g for 15 minutes at room temperature. After separation, the serum samples were analysed. HS-CRP levels were measured using nephelometry, a latex Particle Enhanced Turbidimetric Immunoassay technique (PETIA) (NA Latex CRP Kit, Dade Behring, UK). The technique involves combining antibodies against CRP with sera, the aggregation of CRP with antibodies increases its turbidity which is then measured with spectrometry at 340 $\mathrm{nm}$. The assay had sensitivity to detect as low as $0.5 \mathrm{mg} /$ litre of CRP. Undetectable CRP values were recorded as 0.015 $\mathrm{mg} /$ litre. Levels greater than 1 were considered significant.

\section{Statistical Methods}

The description of data was in the form of mean ( \pm ) SD for quantitative data and frequency and proportion for qualitative data. Student ' $t$ ' test $(t)$ was used for comparison between two groups regarding normally distributed (Parametric) quantitative data. Pearson correlation coefficient test (r) was used to test a positive or negative relationship between two variables. Results were considered significant if $\mathrm{P}<0.05$. Association between the size of infarct and hs-CRP levels were analysed using Analysis Of Variance (ANOVA) test.

\section{Sex Distribution of Patients in the Study}

In the present study population there were totally 100 patients, of whom 61 were males and 39 were females. Of the 61 males there were 13 with haemorrhage, 48 males having ischaemic infarct. Of the 39 females, there were 16 haemorrhage and 23 with ischaemic infarct.

\begin{tabular}{|c|c|c|c|c|}
\hline Diagnosis & Sex & $\begin{array}{c}\text { Mean Hs- } \\
\text { CRP(mg/L) }\end{array}$ & $\begin{array}{c}\text { Std. } \\
\text { Deviation }\end{array}$ & N \\
\hline \multirow{3}{*}{ Haemorrhagic } & Male & 2.6308 & 0.96641 & 13 \\
& Female & 2.6813 & 0.61872 & 16 \\
& Total & $\mathbf{2 . 6 5 8 6}$ & $\mathbf{0 . 7 7 8 4 6}$ & $\mathbf{2 9}$ \\
\hline Ischaemic & Male & 7.5433 & 2.98096 & 48 \\
\hline & Female & 6.8813 & 2.82758 & 23 \\
\hline & Total & $\mathbf{7 . 3 2 8 9}$ & $\mathbf{2 . 9 2 8 5 7}$ & $\mathbf{7 1}$ \\
\hline
\end{tabular}

Table 1: Sex Distribution of Patients in the Study and Mean Hs-CRP Levels in Males and Females

$\mathrm{N}$ - No. of patients

1. The mean hs-CRP in males was $6.49 \mathrm{mg} / \mathrm{lt}$ and that in females was $5.15 \mathrm{mg} / \mathrm{lt}$. In males, the hs-CRP was significantly higher compared to females $(\mathrm{p}=0.46)$.

2. $85.2 \%$ males and $71.8 \%$ females have more than $3 \mathrm{mg} / \mathrm{L}$ mean hs-CRP.

3. Effect of gender on mean hs-CRP is more in ischaemic stroke than in haemorrhagic stroke.

\section{Age Distribution of Study}

Stroke is more common in the age group 56-75 years (57\%). The mean age for male 54.86 yrs. and female it is 61.52 yrs. There is slightly significant correlation between age and rise in hs-CRP ( $\mathrm{r}=0.23, \mathrm{p}=0.042)$. Maximum number of stroke patients in the age group of 50-59 (31) and 60-69 (28), who had the highest mean hs-CRP values $7.15 \mathrm{mg} / \mathrm{L}$ and $6.42 \mathrm{mg} / \mathrm{L}$.

\section{Stroke Patients with Different Risk Factors}

In our study 46 patients had hypertension, 38 had diabetes, 35 patients had dyslipidaemia, 32 were smokers, 36 consumed alcohol and 16 had no risk factors. A significant number of patients had multiple risk factors, 19 patients had more than three risk factors, 29 patients had more than two risk factors.

All the patients in this study has more than $1 \mathrm{mg} / \mathrm{L}$ hs-CRP levels; 80 patients are having raised hs-CRP levels ( $>3 \mathrm{mg} / \mathrm{L})$, in which 71 had ischaemic stroke and 9 had haemorrhagic stroke; 20 patients had medium hs-CRP levels (1-3 mg/L). This was seen in haemorrhagic stroke patients. Mean hs-CRP in this study is $5.97 \mathrm{mg} / \mathrm{L}$.

\section{Mean Hs-CRP in Haemorrhagic Stroke and Ischaemic Stroke}

In our study, there are 29 haemorrhagic stroke and 71 ischaemic stroke patients. Mean hs-CRP in ischaemic stroke patients is $7.32 \mathrm{mg} / \mathrm{L}$ and haemorrhagic stroke is $2.65 \mathrm{mg} / \mathrm{L}$, which is statistically highly significant $(\mathrm{p}<0.001)$.

\section{Mean Hs-CRP in Stroke Patients with Hypertensives and Non-Hypertensives}

In our study there were 46 hypertensives, 12 of them have haemorrhagic stroke and 34 have ischaemic stroke.

\section{Mean Hs-CRP in Stroke Patients with Diabetes and Non- Diabetes}

There were total of 38 diabetics and 62 non-diabetics in the study; 10 patients with diabetes had haemorrhagic stroke and 28 had ischaemic stroke.

\section{Effect of Dyslipidaemia on Mean Hs-CRP in Haemorrhagic} and Ischaemic Stroke

In our study 35 patients had dyslipidaemia and 30 patients with dyslipidaemia had ischaemic stroke, while 5 of them had haemorrhagic stroke.

\section{Mean Hs-CRP Levels in Stroke Patients with Alcoholism}

In our study, 36 patients consumed alcohol and 64 did not; 8 stroke patients with alcoholism had haemorrhagic stroke and 28 had ischaemic stroke.

In our study, 36 patients consumed alcohol and 64 did not; 8 stroke patients with alcoholism had haemorrhagic stroke and 28 had ischaemic stroke. The mean hs-CRP in those who consumed alcohol was $7.22 \mathrm{mg} / \mathrm{lt}$, which was higher than that who did not $5.27 \mathrm{mg} / \mathrm{lt}$. This was significant $(\mathrm{T}=2.41, \mathrm{DF}=98$, $\mathrm{p}=0.009$ ).

There is statistically significant difference in mean hs-CRP levels in ischaemic stroke $(p=0.012)$ also, but not in haemorrhagic stroke $(\mathrm{p}=0.57) ; 83.3 \%$ of stroke patients with alcoholism have more than $3 \mathrm{mg} / \mathrm{L}$ hs-CRP effect of smoking on mean hs-CRP in ischaemic and haemorrhagic stroke.

In this study, there were 32 smokers of whom 11 had haemorrhagic stroke and 21 had ischaemic stroke. The mean hs-CRP in smokers was very high, $7.16 \mathrm{mg} / \mathrm{lt}$. This was significant when compared to non-smokers, that is $5.41 \mathrm{mg} / \mathrm{lt}$ with ( $\mathrm{p}=0.025)(\mathrm{T}=2.55, \mathrm{DF}=98, \mathrm{p}=0.025)$. There is statistically significant difference in mean hs-CRP levels in ischaemic stroke $(\mathrm{p}=0.004)$ also, but not in haemorrhagic stroke ( $p=0.628) ; 84.4 \%$ of smokers have more than $3 \mathrm{mg} / \mathrm{L}$ hs-CRP.

\section{Mean Hs-CRP in Patients with Other Risk Factors}

In this study there are 16 patients without any of the above mentioned risk factors as we only considered hypertension, 
diabetes, alcoholism, dyslipidaemia and smoking. These patients may have other risk factors, which we have not considered in this study. So we also analysed such patients; there were 16 such patients, 7 of whom had ischaemic infarcts and 9 had haemorrhage.

\section{Mean Hs-CRP Levels with Size of Infarct}

$\mathrm{F}=299.422 \mathrm{p}<0.001$ Bonferroni multiple comparison Hs-CRP was significantly higher in patients with large ischaemic stroke patients $9.155 \mathrm{mg} / \mathrm{lt}$ than in those with lacunar stroke patients $4.97 \mathrm{mg} / \mathrm{lt}$ and haemorrhagic stroke patients $2.65 \mathrm{mg} / \mathrm{lt}$.
This difference was statistically significant. Haemorrhagic lacunar infract $\mathrm{p}<0.001$, haemorrhagic-large infarct $\mathrm{p}<0.001$, lacunar infract-large infarct $\mathrm{p}<0.001$.

\section{Mean Hs-CRP Levels and Outcome and Mortality}

In this study mortality was $28 \%$ (28 deaths), of this 10 were haemorrhagic stroke (34\%) patients and 18 were ischaemic stroke $(25 \%)$ patients and we could not trace outcome of 4 patients ( 3 haemorrhagic and 1 ischaemic patient).

\begin{tabular}{|c|c|c|c|c|}
\hline Name of the Study & No. of Patients & Mean Age+SD & Timing of Hs-CRP Sampling & Mean Hs-CRP \pm SD \\
\hline Present Study & $100(\mathrm{H}-29, \mathrm{I}-71)$ & $56.26 \pm 11$ & $<12 \mathrm{hrs}$. & $5.97 \pm 3.28 \mathrm{mg} / \mathrm{L}$ \\
\hline Shoaeb et al & $50(\mathrm{H}-25, \mathrm{I}-25)$ & $59.5 \pm 8.6$ & $<24 \mathrm{hrs}$. & $7.6 \pm 4.9 \mathrm{mg} / \mathrm{L}$ \\
\hline Roudbary et al & $32(\mathrm{H}-16, \mathrm{I}-16)$ & $70.9 \pm 9.4$ & $<24 \mathrm{hrs}$. & $10.79 \mathrm{mg} / \mathrm{L}$ \\
\hline Mishra et al & $40(\mathrm{H}-26, \mathrm{I}-14)$ & 55.53 & $<72 \mathrm{hrs}$. & $8.02 \pm 5.08$ \\
\hline \multicolumn{7}{|c|}{ Table 2: Discussion - Comparison of Age, Sampling Timing, Mean Hs-CRP } \\
\hline
\end{tabular}

H-Haemorrhagic stroke, I-Ischaemic stroke

Stroke itself causes elevation of hs-CRP after 12 to 74 hours of onset, 16 so studies with late measurement of hs-CRP have high levels of hs-CRP compared with earlier studies. This findings are comparable with Shoaeb et al,12 Mishra et al,11 whereas high levels in Roudbary et al 17 may be explained by older age of study population and relatively small study population.

In the present study, $80 \%$ of patients had hs-CRP levels greater than $3 \mathrm{mg} / \mathrm{L}$. All the ischaemic stroke patients had more than $3 \mathrm{mg} / \mathrm{L}$ (high) hs-CRP level, whereas 32\% haemorrhagic stroke had hs-CRP levels greater than $3 \mathrm{mg} / \mathrm{L}$. We found no studies on prevalence of hs-CRP in haemorrhagic stroke. Several studies have varying prevalence of hs-CRP in ischaemic stroke.

\begin{tabular}{|c|c|c|}
\hline Study & $\begin{array}{c}\text { Ischaemic } \\
\text { Stroke }\end{array}$ & $\begin{array}{c}\text { Haemorrhagic } \\
\text { Stroke }\end{array}$ \\
\hline $\begin{array}{c}\text { Present Study } \\
(\mathrm{CRP}>3 \mathrm{mg} / \mathrm{L})\end{array}$ & $100 \%$ & $32 \%$ \\
\hline $\begin{array}{c}\text { Chaudhuri (CRP > } \\
\mathrm{mg} / \mathrm{L})\end{array}$ & $60 \%$ & - \\
\hline $\begin{array}{c}\text { Rajput et al } \\
(\mathrm{CRP}>10 \mathrm{mg} / \mathrm{L})\end{array}$ & $88 \%$ & - \\
\hline $\begin{array}{c}\text { Di Napoli et al } \\
(\mathrm{CRP}>0.5 \mathrm{mg} / \mathrm{dL})\end{array}$ & $74.2 \%$ & - \\
\hline $\begin{array}{c}\text { Muir et al (CRP > } 10 \\
\text { mg/L) }\end{array}$ & $42.1 \%$ & - \\
\hline $\begin{array}{c}\text { Dewan KR et al } \\
\text { (CRP > 3 mg/L) }\end{array}$ & $62 \%$ & - \\
\hline $\begin{array}{c}\text { Table 3: Discussion - Comparison of CRP Positive } \\
\text { Prevalence }\end{array}$ \\
\hline
\end{tabular}

This variance could be explained partly by the different definitions of high CRP in various studies, duration of stroke and age of study population. The hs-CRP level is now universally standardised and most centres accept a value above $3 \mathrm{mg} / \mathrm{L}$ as high

Hs-CRP has been established as a risk factor for vascular pathology of brain. In this study, hs-CRP levels measured within $12 \mathrm{hrs}$. of onset of symptoms is presumed to be near baseline level. So all patients in this study had more than 1 $\mathrm{mg} / \mathrm{L}$ baseline hs-CRP, which comes under moderate risk group; $80 \%$ patients had high risk hs-CRP levels. These findings are in agreement with Hisayama Study, Framingham Study. ${ }^{13}$ Inflammation is central process in atherosclerosis and ischaemic stroke; inflammatory markers like hs-CRP frequently elevated in ischaemic stroke patients.

Elevated hs-CRP is more commonly seen in ischaemic stroke than haemorrhagic stroke. In haemorrhagic stroke, atherosclerosis role is limited; main cause for haemorrhagic stroke is hypertension, lipohyalinosis, cerebral amyloid angiopathy and fibrinoid necrosis.

Hs-CRP is also a useful marker for differentiating ischaemic and haemorrhagic strokes as shown in the study.

\begin{tabular}{|c|c|c|}
\hline $\begin{array}{c}\text { Name of } \\
\text { Study }\end{array}$ & $\begin{array}{c}\text { Haemorrhagic } \\
\text { Stroke } \\
\text { Mean Hs-CRP } \pm \text { SD }\end{array}$ & $\begin{array}{c}\text { Ischaemic Stroke } \\
\text { Mean Hs-CRP in } \\
\text { 土SD }\end{array}$ \\
\hline $\begin{array}{c}\text { Present } \\
\text { Study }\end{array}$ & $2.65 \pm 0.77 \mathrm{mg} / \mathrm{L}$ & $7.32 \pm 2.92 \mathrm{mg} / \mathrm{L}$ \\
\hline Shoaeb et al & $6.2 \pm 3.8 \mathrm{mg} / \mathrm{L}$ & $9 \pm 5.5 \mathrm{mg} / \mathrm{L}$ \\
\hline $\begin{array}{c}\text { Roudbary et } \\
\text { al }\end{array}$ & $2.65 \pm 1.70 \mathrm{mg} / \mathrm{L}$ & $18.92 \pm 11.28 \mathrm{mg} / \mathrm{L}$ \\
\hline Mishra et al & $11.27 \pm 7.67 \mathrm{mg} / \mathrm{L}$ & $6.7 \pm 3.11 \mathrm{mg} / \mathrm{L}$ \\
\hline \multicolumn{2}{|c|}{ Table 4: Discussion - Comparison Mean Hs-CRP in } \\
Ischaemic and Haemorrhagic Stroke
\end{tabular}

Mean hs-CRP levels are considerably higher in ischaemic stroke than in haemorrhagic stroke. This difference is due to different pathological mechanism involved. All the above studies have similar result except Mishra et al. The author himself told that this difference is due to presence of confounding factors like obesity, elderly age and large size of the bleed secondarily leading to ischaemia and increase in hsCRP level.

Moreover, hs-CRP levels are also used for predicting poor outcome of patient in both ischaemic and haemorrhagic stroke. Patient with unfavourable outcome had more hs-CRP levels compared with patient with favourable outcome both in ischaemic stroke and haemorrhagic stroke. We found only two studies in this regard Shoaeb et $\mathrm{al}^{18}$ and Mishra et al ${ }^{11}$; both these studies found similar results. Outcome measured in terms of survivors and non-survivors in this study and Mishra et al, but in Shoaeb et al used mRS and BI to measure outcome 
as favourable and non-favourable outcome.

\begin{tabular}{|c|c|c|c|c|}
\hline \multirow{2}{*}{$\begin{array}{l}\text { Name of } \\
\text { study }\end{array}$} & \multicolumn{2}{|c|}{$\begin{array}{l}\text { hemorrhagic stroke } \\
\text { Mean hs-CRP } \pm S D\end{array}$} & \multicolumn{2}{|c|}{$\begin{array}{l}\text { ischemic stroke } \\
\text { Mean hs-CRP } \pm S D\end{array}$} \\
\hline & favorable & Unfavorable & favorable & Unfavorable \\
\hline $\begin{array}{l}\text { Present } \\
\text { study }\end{array}$ & 2.39 (surv) & 3.21 (non-sur) & 6.46(surv) & 9.90(non-sur) \\
\hline $\begin{array}{c}\text { Shoaeb et al } \\
m R S>2 \\
B \mid<95\end{array}$ & $\begin{array}{l}5.3 \pm 2.5(m R S<2) \\
5.8 \pm 2.6(\mathrm{~B} \mid>95)\end{array}$ & $\begin{array}{l}6.9 \pm 4.6(\mathrm{mRS}>2) \\
6.3 \pm 4.4(\mathrm{Bl}<95)\end{array}$ & $\begin{array}{l}7.1 \pm 4(m R S<2) \\
4.9 \pm 1.6(B \mid>95)\end{array}$ & $\begin{array}{l}13 \pm 6.3(\mathrm{mRS}>2) \\
11.8 \pm 5.4(\mathrm{Bl}<95\end{array}$ \\
\hline $\begin{array}{l}\text { Roudbary et } \\
\text { al }\end{array}$ & - & - & - & - \\
\hline Mishra et al & $\begin{array}{l}6.9 \pm 3.8 \\
\text { (surv) }\end{array}$ & \begin{tabular}{|l|}
$14.8 \pm 6.2$ \\
(non-sur)
\end{tabular} & $\begin{array}{l}3.02 \pm 1.9 \\
\text { (surv) }\end{array}$ & \begin{tabular}{|l|}
$10.7 \pm 5.4$ \\
(non-sur)
\end{tabular} \\
\hline
\end{tabular}

Table 5: Discussion - Comparison of Mean Hs-CRP and Outcome

Elevated hs-CRP level not only indicates severity of disease process, but also ligand-bound CRP activates the classical complement pathway, binds to immunoglobulin receptors on immune cells, and activates cytokine production and complement related inflammatory reactions that may exacerbate inflammatory ischaemic injury. Thus, it is a prognostic marker in stroke.

The ischaemic group patients with smoking, diabetes, hypertension, dyslipidaemia, alcoholism have significantly higher hs-CRP levels as compared to those who do not have the above risk factors.

All stroke patients with above risk factors had more than $80 \%$ hs-CRP positive levels $(3 \mathrm{mg} / \mathrm{L}$ ). Thus, person with a vascular risk factor with elevated hs-CRP had increased risk of stroke when compared with risk factor alone. This association is clearly seen in ischaemic stroke, not in haemorrhagic stroke. These findings are in agreement with Roudbary et al, Hisayama Study and Framingham Study. This may be due to elevated hs-CRP levels may reflect the existence of advanced atherosclerosis.

Induced by other vascular risk factors, increased risk of stroke due to enhanced atherogenic effect of inflammation in arterial walls, which has already been damaged by other risk factors, whereas no clear association is seen in Mishra et al and Shoaeb et al. This is due to delayed presentation, older age of study population, obesity, elderly age and large size of the bleed.

Thus, addition of hs-CRP to this risk factor profile increases prediction rate. People with lacunar stroke have a low level of hs-CRP as compared to large vessel stroke. Compared to large artery atherosclerosis, the prevalence of high hs-CRP levels was lower among stroke patients due to small vessel disease. Chaudhuri et al, ${ }^{17}$ Hertog et al ${ }^{16}$ and Muir et al ${ }^{19}$ also found same results; cause of this association may be secondary to unknown interactions with genetic and environmental pathogenic factors.

\section{CONCLUSION}

1 There was good correlation of hs-CRP and inflammatory burden in ischaemic stroke and to some extent in haemorrhagic stroke.

2 The inflammatory burden, however, was much higher in ischaemic stroke with risk factors than in haemorrhagic stroke with risk factors.

3 Hs-CRP was found to correlate well with conventional established risk factors in ischaemic stroke, but not in haemorrhagic stroke.
4 Hs-CRP was found to be a use of full biomarker to differentiate between haemorrhagic and ischaemic stroke.

5 High admission hs-CRP levels are associated with large infarct and high death rates.

1 Thus hs-CRP may be a useful marker for prediction, diagnosis and prognostication in stroke.

2 However, further large scale studies are required to confirm these findings.

\section{SUMMARY}

The present study was done to evaluate the inflammatory burden in stroke. This is a cross-sectional study; 100 consecutive acute stroke patients who presented within 12 hrs. to the MGM Hospital, Warangal, Telangana are considered in this study. Taking into selection and exclusion criteria, stroke was diagnosed clinically and later confirmed radiologically.

Blood sample for hs-CRP was taken at the time of admission and hs-CRP levels measured after radiological confirmation using nephelometry method. There were 71 ischaemic stroke patients and 29 haemorrhagic stroke patients in whom all ischaemic stroke patients $71(100 \%)$ and 9 (32\%) haemorrhagic stroke patients has high hs-CRP (3 $\mathrm{mg} / \mathrm{L})$. Mean hs-CRP levels in ischaemic stroke was $7.32 \pm 2.92$ $\mathrm{mg} / \mathrm{L}$ and haemorrhagic stroke was $2.65 \pm 0.77 \mathrm{mg} / \mathrm{L}$, which was statistically significant $(p<0.001)$. In this study, hypertension- 46 is the leading risk factor followed by diabetes-38, dyslipidemia-35, alcoholism-36 and smoking-32; $93 \%$ of hypertensives, $86.8 \%$ diabetics, $94 \%$ dyslipidemic patients, $82 \%$ alcoholics and $83 \%$ smokers have more than 3 $\mathrm{mg} / \mathrm{L}$ hs-CRP. Difference mean hs-CRP in all stroke patients with above risk factors is statistically significant. The difference is statistically significant in ischaemic stroke also, but in haemorrhagic stroke patients only hypertensive patients have significant high levels of hs-CRP. The difference in mean hs-CRP levels is considerably higher in non-survivor than survivor.

\section{REFERENCES}

1 WHO. Technical Report Series. 1976:469.

2 Sharma SK, Agarwal AK, Gupta P, et al. API textbook of medicine.10th edn. New Delhi: Jaypee Brother 2015;1912.

3 Smith WS, Stephen, Hauser SL. Cerebrovascular disease. In: Harrison's principles of internal medicine. $16^{\text {th }}$ edn. New York: McGraw-Hill 2015:1374.

4 Roger VL, Go AS, Lloyd-Jones DM, et al. Heart disease and stroke statistics-2011 update: a report from the American heart association. Circulation 2011;123(4):e18-e209.

5 Pandian JD, Sudhan P. Stroke epidemiology and stroke care services in India. Journal of Stroke 2013;15(3):128-134.

6 Coull BM. Inflammation and stroke-Introduction. Stroke 2007;38(part 2):631.

7 Jordán J, Segura T, Brea D, et al. Inflammation as therapeutic objective in stroke. Current Pharmaceutical Design 2008;14:3549-3564.

8 Zieman SJ, Melenovsky V, David A. Kass. Mechanisms, pathophysiology and therapy of arterial stiffness. Arterioscler Thromb Vasc Biol 2005;25(5):932-943.

9 Elkind MS, Tai W, Coates K, et al. High-sensitivity Creactive protein, lipoprotein-associated phospholipase A2 and outcome after ischemic stroke. Arch Intern Med 2006;166(19):2073-2080. 
10 Singh VK, Haria JM, Jain SK. C-reactive protein in ischemic stroke - an experimental study. Int J Sci Stud 2014;2(1):2527.

11 Mishra PT, Chandra R, Saxena SK, et al. High sensitivity Creactive protein (hs-CRP) level in cerebrovascular accident (Stroke). JIACM 2010;11(3):204-7.

12 Shoaeb MA, Shehata MA, Taema KM, et al. CRP in cerebrovascular stroke: prognostic implications. The Egyptian Journal of Critical Care Medicine 2014;2(1):4352.

13 Rost NS, Wolf PA, Kase CS, et al. Plasma concentration of Creactive protein and risk of ischemic stroke and transient ischemic attack. The Framingham study. Stroke 2001;32(11):2575-2579.

14 Ridker PM, Cushman M, Stamper MJ, et al. Inflammation, aspirin and the risk of cardiovascular disease in apparently healthy men. N Engl J Med 1997;336(14):973-979.
15 Ridker PM, Nader R, Lynda R, et al. Comparison of Creactive protein and low-density lipoprotein cholesterol levels in the prediction of first cardiovascular events. $\mathrm{N}$ Engl J Med 2002;347(20):1557-1565.

16 den Hertog HM, van Rossum EJA,van der Worp HB, et al. Creactive protein in the very early phase of acute ischemic stroke: association with poor outcome and death. J Neurol 2009;256(12):2003-2008.

17 Chaudhuri JR, Mridula KR, Umamahesh M, et al. High sensitivity C-reactive protein levels in acute ischemic stroke and subtypes: a study from a tertiary care center. Ir J neurol 2013;12(3):92-97.

18 Roudbary SA, Saadat F, Forghanparast K, et al. Serum Creactive protein level as a biomarker for differentiation of ischemic from hemorrhagic stroke. Acta Medica Iranica 2011;49(3):149-152.

19 Muir KW, Weis CJ, Alwan W. C-Reactive protein and outcome after ischemic stroke. Stroke 1999;30(5):981985. 